
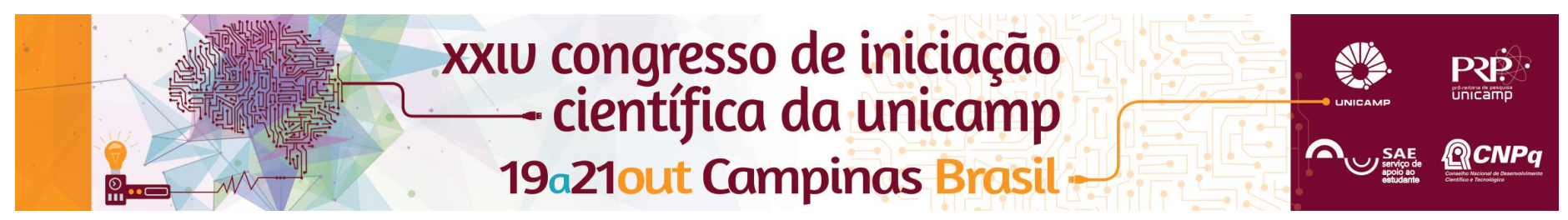

\title{
Características físico-químicas das proteínas do glúten vital de diferentes origens
}

\author{
Karoline Urbano*, Fernanda Ortolan, Caroline Joy Steel
}

\section{Resumo}

No Brasil, o glúten vital (GV) usado para melhorar as características reológicas de farinhas é comercializado com poucas informações referentes à sua qualidade proteica. $O$ objetivo deste trabalho foi avaliar as características físicoquímicas e estruturais das proteínas de GV de diferentes origens (GVA e GVB), através de composição aminoacídica, eletroforese, propriedades térmicas de desnaturação e avaliação microscópica da rede de glúten (MEV). Tanto GVA quanto GVB apresentaram resultados semelhantes em relação à composição aminoacídica e distribuição molecular de suas proteínas. Diferenças no comportamento elástico frente à varredura de temperatura, e também na estrutura da rede de glúten foram observadas, sendo que GVA apresentou os melhores resultados, reforçando a existência de diferenças na qualidade dos glútens vitais comercializados.

\section{Palavras-chave:}

glúten vital, qualidade, proteínas.

\section{Introdução}

O glúten vital de trigo é comercializado como um ingrediente que pode ser adicionado às farinhas que apresentam baixa qualidade para a elaboração de pães, ou ainda aos pães ricos em fibras. No Brasil, o glúten comercializado não é classificado de acordo com o seu perfil proteico ou com a qualidade de suas proteínas, mas pelo teor proteico total. O objetivo deste trabalho foi avaliar as características físico-químicas e estruturais das proteínas de glúten vital comercial de diferentes origens (GVA e GVB), através de composição aminoacídica, eletroforese, propriedades térmicas de desnaturação e MEV.

\section{Resultados e Discussão}

A composição aminoacídica foi determinada para avaliar os aminoácidos que constituem as proteínas dos glútens vitais. Os resultados encontrados para GVA e GVB apontam que não há grandes diferenças na quantidade de aminoácidos que os constituem. No trigo, as albuminas, globulinas, gliadinas e gluteninas são proteínas heterogêneas, não apenas em função da variedade de proteínas que constituem essas frações, mas também em virtude de sua composição em aminoácidos (HOSENEY, 1994).

Nos resultados obtidos na eletroforese, podemos verificar que GVA e GVB apresentaram resultados similares, destacando-se as proteínas presentes nas bandas de 21,5 a $31 \mathrm{kDa}$ ( $\alpha$-, $\beta$ - e $\gamma$ - gliadinas) e na banda de 97,4 kDa (gluteninas) (GUERRIERI et al., 1996).

Na determinação das propriedades térmicas de desnaturação das proteínas do glúten vital foi possível verificar as temperaturas onde ocorrem as mudanças estruturais nas proteínas que constituem os glútens vitais, levando à sua desnaturação. Os resultados dessa análise demonstram que GVA apresentou maior DOI: 10.19146/pibic-2016-50982 comportamento elástico (G') e estabilidade térmica, quando exposto a um aumento de temperatura, comparado a GVB. As temperaturas de desnaturação foram próximas a $60{ }^{\circ} \mathrm{C}$ para as gliadinas e $80{ }^{\circ} \mathrm{C}$ para as gluteninas.

A MEV nos permitiu observar a formação da microestrutura da rede do glúten. Foi possível observar que GVA apresentou rede proteica com maior número de alvéolos, mas de menor tamanho, enquanto que GVB apresentou rede proteica com menor número de alvéolos, mas de maior tamanho, com uma estrutura mais coesa/viscosa que GVA. Essas diferenças provavelmente estão relacionadas com os teores de gliadinas e gluteninas das amostras.

\section{Conclusão}

A partir dos resultados, pode-se verificar que, mesmo com resultados similares para alguns testes, as amostras de glúten vital apresentaram diferenças estruturais significativas. GVA apresentou-se com melhor característica viscoelástica e possivelmente de melhor qualidade para panificação que GVB. Conclui-se, desta forma, que existem diferenças entre as amostras comerciais de glúten vital de diferentes qualidades que são comercializadas no Brasil.

\section{Agradecimentos}

As autoras agradecem ao CNPq pela concessão da bolsa de Iniciação Científica (PIBIC) e da bolsa de Doutorado.

GUERRIERI, N. et al. Use of spectroscopic and fluorescence techniques to assess heat-induced molecular modifications of gluten. Cereal Chemistry, v. 73, n. 3, p. 368-374, 1996.

HOSENEY, R.C. Principles of cereal science and technology. 2nd ed. St. Paul: American Association of Cereal Chemists, AACC, 1994. 